\begin{tabular}{llllllll}
\hline $\mathbf{N}$ & $\mathbf{E}$ & $\mathbf{T}$ & $\mathbf{W}$ & $\mathbf{O}$ & $\mathbf{R}$ & $\mathbf{K}$ & $\mathbf{S}$ \\
\hline
\end{tabular}

\title{
ETHNOGRAPHY / LISTENING / RECORDING SOUND ENVIRONMENTS OF THE MALAWIAN NORTH AND BEYOND
}

\author{
PIOTR CICHOCKI
}

\section{INSTITUTE OF ETHNOLOGY AND CULTURAL ANTHROPOLOGY, UNIVERSITY OF WARSAW}

\begin{abstract}
Anthropological writings barely comment on practices of listening and recording that are in fact essential for ethnographic fieldwork. They constitute the foundations of encountering the local environments approached by ethnographers. This research practice recontextualizes recorded sound in the new settings of academic or commercial repositories. Two case studies from fieldwork in Northern Malawi elucidate ways in which reflective listening and the utilization of technology constitute knowledge generative processes. The example of the recordings entitled "Bicycling through Chibavi" concerns questions of distance and engagement during fieldwork. The case of an experimental recording of vimbuza music constitutes a methodological project of a "situationist event". The project demonstrates how the subjects of the research performatively navigate between local sound environments.
\end{abstract}

K E Y W O R D S : anthropology of sound, sound studies, technology, archive, Malawi, Africa

Local sound environments differ significantly from one another. Likewise, the relationships between people and their (sound) environments are remarkably varied. The act of listening constitutes an essential performance of one's relationship with the environment and furthermore is an act of the social construction of reality. Given the continuity between everyday life experience and ethnographic methods, listening also comprises a part of participant observation, even though the name for this method is based on a visual metaphor (Rice 2003). The modern aural experience of any environment also includes recording and playback, involving the use of various technologies and coding methods. This applies not just to human speech, but also implicitly to every sound registered by the human ear or a similar device. In the era of modern registration technologies, listening and recording have been irreversibly entangled, and the distinction between them has become blurred. 
The injunction that ethnographic method should be a continuation of everyday life experience refers also to the use of technologies. For example, sound recording is a component of ethnographic research, in forms ranging from the taping of ethnographic interviews to the use of more complex registration technology to capture particular acoustic phenomena. However, more often than not audio recording in ethnography has been treated as a virtually transparent process of documentation. In contrast, I intend to critically re-think the role of sound registration in our discipline. In this paper, I problematize the recording of sound during ethnographic fieldwork and think through the implications of this for research methodology. The aim is to place sound recording practices at the forefront of the research method. Recording, I argue, can reveal or generate other cultural practices, by turning them into objects of ethnographic knowledge. These emerging practices are not free from issues of hierarchy; however, increasing awareness of recording processes can generate means to negotiate with, contest, or challenge existing instances of power. In the following pages, I explain these methodological propositions for the ethnographic research of sound environments. I use my fieldwork concerning rural and urban sound environments in Northern Malawi as an example. The methodological direction proposed, I argue, can widen our understanding of what anthropological knowledge is, or may be, in relation to listening and recording. To unpack this project, I start with a discussion of the mediating character of ethnographic work, which connects local sound environments with technologized repositories. In order to do so, I firstly review the concept of the sound environment and its connection to human subjects.

\section{SOUND ENVIRONMENTS AND REPOSITORIES}

Broadly speaking, the term "sound environment" refers to the relations generated by sound between entities in a given environment. In more detail, I present here three characteristics of the sound environment that are significant for ethnographic research of listening.

The first characteristic of the sound environment is its spatiality. Deleuze and Guattari discuss sound as a way of living the relation with the environment (Deleuze and Guattari 1987, 310-350). According to these authors, the environment urges its inhabitant firstly to attune, to respond and then to actively engage. Both listening to and producing a sound constitute profound practices of engagement. These practices are also particularly important for creating the difference between the interior and exterior of a certain territory. As an example, I imagine a group of workers in a forest, willingly or unintentionally announcing their presence and thus affecting the ecological environment. Their presence is marked by its acoustic dimension (not to mention the 
other long-term effects of their intrusion). The spatial nature of a sound environment implies physicality. However, due to the development of technologies for sound production and distribution, it is also necessary to take virtual or imagined spaces into account. These spaces function, for example, through information technologies, as I describe in more detail in the following pages. Amongst exemplary spaces of this kind might be mentioned the ephemeral "sonic afro-modernity" that spread across continents (Weheliye 2005) or the noise music scene that connects listeners in multiple physical places (Novak 2013).

This leads us to the second feature of the sound environment, which is the physicality involved in its perception. Listening requires the presence and involvement of the body or its mediatizations. Novak describes the listening process as always corporeal, regardless of whether it takes place at a concert or in a lonely room through headphones (Novak 2013, 4-5). Physical involvement in the environment can be ambiguous, especially in our technically saturated modernity. For example, a person listening to music on headphones on crowded city public transport is placed in two environments at the same time: the space of music and a different physical locality. However, this does not change the fact that listening is always embodied, notwithstanding the form and source of the sound. Tim Ingold emphasizes that embodiment does not mean limiting aural experience to a single organ of hearing, but rather involves the immersion of the whole organism in a certain specific space (Ingold 2007). This applies regardless of whether the environment exists independently of human activity, such as the rainforest constituting the world of the Kaluli described by Steven Feld (Feld 1982), or in highly urbanized and mechanical surroundings, such as offices (Dibben and Haake 2013) or modern concert halls (Thompson 2008).

The third characteristic of the sound environment to be noted here is its social and intersubjective construction. Peter Sloterdijk draws on the threads mentioned above when describing the sonic dimension of a social environment, which he designates as a phonotop. A phonotop separates a human community from that which is external to it: it creates a sense of immersion in a familiar, socially constructed sound world, through such features as a native tongue, as well as other human and non-human sounds (Sloterdijk 2016, 362-400) ${ }^{\text {r }}$.

The key question in the context of this research is how these features affect the ethnographic research of sound environments. I believe that the key to understanding this problem is to examine the relationship between sound environments and ethnographic accounts. Recording and storage technologies play a key role here.

I Such a distinct boundary between the internal realm of any culture and its outsides can undoubtedly be reprimanded as an essentialization. However, for this discussion, it is important to grasp the intersubjective emergence of a social boundary. 
Jonathan Sterne explains that the development of recording devices, like the microphone, forged a new hearing subjectivity. This new subjectivity was the result of the interaction between bodies and technologies (Sterne 2015, 69-70). Moreover, this emergence marked the split of sound away from its immediate physical source. The possibility of the recording and playback of sound away from its initial resonance reconfigured the sense of being in a specific time and space for the listener. Likewise, the use of sound recording devices during ethnographic field research means that elements of the localized, embodied and intersubjective experiences of the fieldwork are transformed into entirely different, evocative objects - for example, digital audio files. After Derrida, I emphasize that this iteration between experience and representation requires varied kinds of technological memorization and methods of storage. In elucidating this, the French philosopher noted that memory functions through the recording of a "trace" of experience. I suggest that this understanding can helpfully be applied to the oscillation between internal and external memories. The comparison between ethnographic recording technologies and memory might therefore be framed as follows: a technologically adjusted trace is objectified by recording and external storage technologies (Derrida 1996).

This description applies both to ethnographers who only tape their interviews and to those who produce field-recordings in a given location. One can describe the memory of listening ethnographers as embodied or internal, while the sound objects registered by recording devices can be treated as external and stored outside the body. This terminology indicates how the process of memorization is technologized during fieldwork. However, the two entangled types of memory can in the end elevate what is recorded to an environment that is separated from that of the initial recording. Within this new environment, which I call a repository, recordings achieve new meanings and new connections. The question of these archives, which absorb and reorganize the sound objects, is a separate and significant problem. These issues impact heavily on the ambiguous relationship between ethnographic knowledge and power. Limited by the volume of the article, I am not able to discuss this question in detail: I therefore seek only to highlight and explain problems related to the archiving and redistribution of data.

Through recording, the flow of experiences and sound waves from a particular environment becomes an object. Registered sounds are transferred to a distinct repository, identified as an accumulation of archived knowledge and entertainment intended for public use ${ }^{2}$. Transfers to archives occur under the control of systems of governance (Foucault 1982, I29). Through the history of modernity, these repositories have taken

2 Derrida also comments on the relationship between individual subjectivity and a repository (an archive), noting that the latter extends the internal voice to a public sphere and, by doing so, governs and disciplines it (Derrida 1996). 


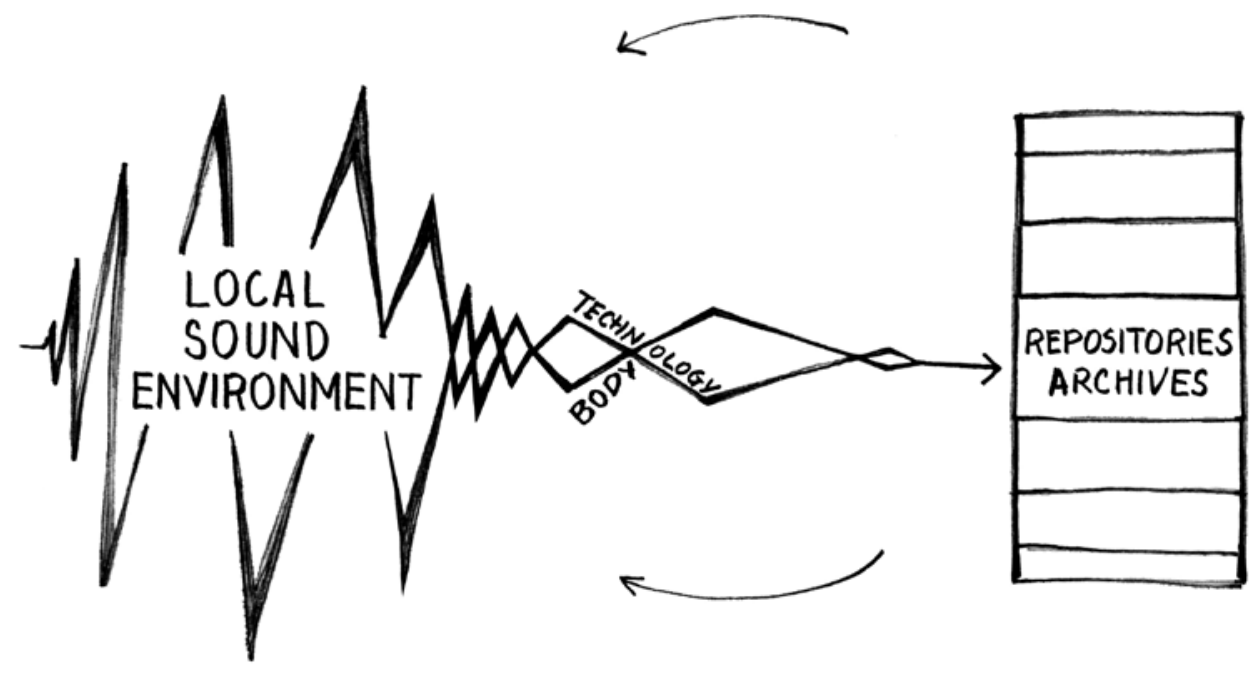

Relations between local sound environments and repositories (drawing by Thuy Duong Dang, Piotr Cichocki)

the form of national or scientific archives, or also commercial catalogues. At the end of the 2oth century, the Internet began to integrate all these repositories into a multidimensional and even more publicly accessible network. I can explain this process through an example of archiving and sharing a field recording, whether this be a piece of music, a soundscape or an authorized interview. At this moment, the recorded sound moves to one or many of the following repositories - a library, a specialized digital database or an Amazon store. From then on, potentially everyone can use this sound object, but on different principles than in the environment in which it was recorded. The ethnographic recording of a religious ceremony during which, for example, a sacrifice or purification was performed can thus become a sound file informing about a certain culture or entertaining a music listener.

Therefore, an ethnographer who records sound plays the ambiguous role of being both an observing participant and a supplier of the repository, and thus s/he performs at and for two separated environments. I assume that understanding these processes informs us about how the relationship between local sound environments and repositories affects our methodologies. This recognition should enable us to reflexively intensify ethnographic method. Also, I argue that it requires a rethinking of modes of participation in sound (and social) environments. As a prelude to recounting the research I conducted in Malawi, in the next part of the article I will propose certain methodological orientations to better elucidate the approach I used. 


\section{METHODOLOGICAL RE-ORIENTATION}

In order to introduce the practice of listening and recording into the reflexive ethnographic method, I refer to a strand of work in our discipline which considers its experimental component as a core value ${ }^{3}$. I argue that ethnographic method not only allows for the objectification of listening and recording practices, but also, by utilizing one method of audio registration or another, takes part in their social construction.

During fieldwork, the relationship with the sound of a certain physical area involves an attunement to multilayered environments (Massumi 20I5). The process of attunement is usually substantial, involving acquiring the social competencies of a local "audiovisual culture" 4 and becoming an active subject within it. Hence, sound ethnographers do not only study and participate in local sound environments, but they may also animate them. Sound environments, as constantly changing processes, are in their essence inclusive. I argue that participation in them is also affected by this processual dynamism. As part of this, research interested in local sound cultures engages varied competencies. These methods should be reorganized in order to contribute to ethnography, without questioning its core values and emancipatory cognitive interest (Habermas 1987). Among the various disciplines potentially enhancing the ethnographic method of studying sound environments, I refer only to applied ethnomusicology', sound engineering, musicianship, composition and sound studies, among others. What is essential for me in this context are changes to methodological paradigms. I argue that this methodological reorientation implies a conceptualization of fieldwork as a network (Shumakher 200I, 255-257) and opens the research process to a situationist approach (Debord 1957). I will discuss these two inclinations in the next sections of the essay.

To illustrate how these approaches contribute to the acquisition of ethnographic knowledge, I narrate two events from a research project I conducted in the northern region of Malawi ${ }^{6}$. The first example concerns how the listening to and recording of

3 Numerous authors have commented on the experimental quality of anthropology (Schneider and Wright 20I0, Faubion and Marcus 2009).

4 I use this term paraphrasing Sarah Pink, who writes about "visual cultures". According to Pink, ethnographers should achieve understanding of these cultures' values and be able to act creatively within them (Pink 200I).

5 Pettan and Titon define applied musicology as: "a music-centered intervention in a particular community, whose purpose is to benefit that community - for example, a social improvement, a musical benefit, a cultural good, an economic advantage, or a combination of these and other benefits. (...) The understanding (...) drives it toward reciprocity [and] is based in the collaborative partnerships that arise from ethnomusicological fieldwork." (Pettan and Titon 2015, 4).

6 Recollecting these events, I decided to adopt a writing technique borrowed from Paul Rabinow's book Reflections on Fieldwork in Morocco (Rabinow 1977). I hold this text in great esteem because of 
a sound environment develops steadily through participation in a social network of relationships. The second case presents the ethnographer co-navigating between physical and virtual sound environments together with members of the researched community. Co-navigation, in this case, was a situationist process that helped the ethnographer to understand the relationship between local sound worlds. At the same time, for other subjects, it gave an opportunity to experimentally, performatively, fuse these environments.

\section{LISTENING THROUGH SOCIAL NETWORKS ON CHIBAVI STREET}

From my first trip down the few kilometre long Chibavi Street during my initial stay in Mzuzu in spring 20I6, my senses were moved by the life of the street and its surroundings. I was fascinated by its dense sound, consisting of layered eruptions of music, prayers, advertisements, electric mills, conversations and the labour of artisans. I travelled this route almost every day, cycling to the city centre from the Luwinga district where I dwelled in the early stages of research.

Soon after, I decided to start regular recordings, aiming to represent my practice of listening. I installed a stereo recorder on my backpack and, at a moderate speed, I pedalled along Chibavir. The intention was to record the moving sound; although in practice the microphone was driven through this vibrating space. In this manner, I created over a dozen recordings, together provisionally entitled "Bicycling through Chibavi"s.

Each of the recordings lasted for about is minutes, as long as it took me to traverse the distance. A stereo microphone captured "what occurred" in the space at the

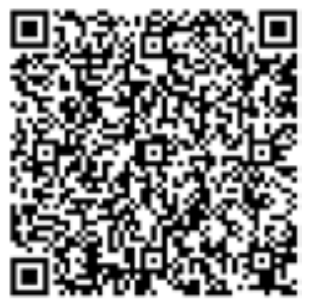

Bicycling through Chibavi moment of my passing. The speed with which I drove limited the length of interactions with people. Because of the motion, my understanding of the conversations I passed was limited to contextless sentences, words or gestures.

its core base in ethnographic material and the researcher's experience, which provide a foundation for further theoretical conceptualizations. In the following examples, the method also emerged from the practice and the interpretation, from the fieldwork.

7 The very basic set up that I used during the first recordings consisted of the Tascam DR-os recorder and a small windshield. At a later stage of work, I also connected the Rode NT-4 microphone to the same recorder.

8 Audio recording Bicycling through Chibavi:

https://rcin.org.pl/Content/I22009/Audio/WA308 I52210 P366 Ethnography-Listenin ooooI.mp3. 
This practice resembled sliding across the surface. As such, recording sound became a method to perceive the place, but it also alienated me from the environment. I was isolated because I did not share in practices typical for inhabitants - in talks, labor, commerce, partying or devotional activities. I moved, only observing and recording glimpses of these practices.

Apart from my role as a passer-by, also the fact that I was a white person on a sportbike (purchased cheaply in Mzuzu, but different than those belonging to Mzuzu professional bicycle taxi drivers, known as sacramento) emphasized the isolation. These circumstances echoed in the recordings. For example, it resounded in the shouts of azungu! (Hey, white person!), that form a counterpart to the constantly audible squeaking of the bicycle chain.

In 2019, I returned to Mzuzu for my next months of fieldwork, planning further recordings of the street. It turned out, however, that the Chibavi area entrapped me more intensely than just through its surface. I was living in the nearby area of Chiputula, and several of my important interlocutors from Chibavi regularly called me to their homes next to the street. Some mentioned that I should learn more through such visits about the everyday life of Mzuzu and Chibavi. One of them commented that my coming into their home was also an act of honouring. During these closer interactions, I started to learn about shortcuts, passages and alleys not visualized on Google maps. Due to my friends, I began to visit churches located along the street, and I used local shops, bars and the services of mechanics. My interlocutors took the roles of guides in this self-revealing environment ${ }^{9}$. The gradual cognition of the street continued also through sensual practices: shared meals in roadside kiosks with fries, listening to music with mp3 sellers, participating in church services, for example on Easter night at the ceremonial bonfire by the local Catholic church. I also recorded some of these micro-events, but the effect remained significantly different from the "Bicycling through Chibavi" recordings.

This constant thickening of contextualized experience shows the role of relationships in the local sound environment. In this sense, social relationships generate meanings. During the first recordings, I listened to the street "aesthetically" and in a way that referred to the properties of physical movement in space. As the recording project advanced, new knowledge began to emerge. This knowledge was generated by the networks of relationships into which I entered. The other actors in the network were parts of the environment of Chibavi Street. In mentioning actors, I mean people who defined me, my research project and their participation in their own ways ${ }^{10}$.

9 Urban anthropology often uses methods of walking and discussing in movement. De Certeau (1984) and Bendiner-Viani (2005) among others described this method in detail.

Io An important role was also played by non-human actors - for example, speakers that blasted noisy cascades of sounds or my own sound recording devices. 
Their activity marked the ethnography not as a venture of an individualistic ethnographer, but rather as a network connecting many participants of different roles, motivations and varying levels of involvement (Schumakher 200I, 255-257). Entering neighbourly relations expanded the network of relationships and generated ethnographic knowledge about the local environment. Through participation in the network of social relations, I slowly transited from an individualistic mode of fieldwork (based on a barely contextualized, but aestheticized attitude) into a connective mode. This connective mode is defined by the ways in which other actors cast my participation. In other words, to a great extent, the environment determined how to approach listening to it.

Although such increased participation meant less regular recordings, it opened up the opportunity to reinterpret earlier recorded sounds through the ways in which my interlocutors understood and experienced them. Any previously recorded sound or noise could reveal potential associations. If the "cycling" sound experience of Chibavi concerned the surface, the second mode enabled an entry into overlapping layers of practice and meaning. I consider these two as complementary modes of fieldwork experience. The surface may enable to embrace the whole; while countless paths into entanglement are potential expansions of small fragments. What allowed the transition from one experience mode to the latter was the strengthening of the network of relations with the environment.

\section{RECORDING AS A SITUATIONIST EVENT}

The second example concerns active participation in the movement between sound environments. These environments concern local music, widely understood. The compass of navigation was vimbuza music - a religious and medical practice prevalent in rural areas of the Malawian north - and the role of co-navigators was held by members of the band Tonga Boys"

I have introduced the band in more detail in other academic (Cichocki 2019) and popular (Cichocki 20I8, Cichocki and Wieczorek 2018) writings, so here I limit myself to a brief presentation of my relationship with them. The group Tonga Boys was formed by minor vendors selling second-hand clothes for Malawians and hand-made souvenirs for whites passing through Mzuzu. Most of the group members spoke Chitonga and identified with the Tonga group, which gave the band its name.

My collaboration with the group can most appositely be described as a situationist event. By this term, I indicate the dynamic character of participation in the researched

II The band consists of Albert Manda, Guta Manda, Peter Kaunda, Myrius Minthall, and Solomon Nikho. In some situations, I partook in the recordings as a supplementary member of the band. 
social reality. For both the researcher and other people from the studied environment, the participation consists in an active anticipation of events and production of their meanings. Therefore, the fieldwork is not only a method to register activities. Ethnographers inevitably participate in this process of production. To apprehend this participation I refer to the term "situationism" that I borrow from Guy Debord. For Debord, "situationism" functioned as the contraposition of modern society, which he defined as spectacular. In the society of the spectacle, centralized power defines the role of the individual as a passive viewer of hegemonic display (Debord 20IO, 7-II). As an antithesis, "situationism" is a political and artistic program of disrupting the hegemonic spectacle by arranging non-spectacular events and participating in them in an embodied way. These actions enable the rejection of the subordination to power, and create opposing, non-hegemonic modes of identification (Debord 1957, 12-15).

Situationism in fieldwork refers to a methodological awareness of undertaking events $^{12}$ in which researchers participate in roles assigned to them by other people from outside the "research staff". As a result, the ethnographer begins to learn the principles of the local social environment (Hastrup 1995, 52-55). A situationist event is an activity in which an ethnographer participates in an initiative or action, co-negotiates its goal or, being aware of possible power asymmetries, creates and assembles necessary infrastructures ${ }^{13}$. Examples of such ethnographic situational practice could be audiovisual performances, especially those in which people from the studied community play a significant, active role, for example as producers, cameramen or directors ${ }^{14}$. Such activity enables cooperation in a network with actors involved in the fieldwork in various, but always autonomous, roles (Schumakher 200I, 255).

This particular situationist event produced ethnographic knowledge about the dynamics of relations between the imagined future and the past, between a rural way

Kirsten Hastrup, who was interested in everyday situations, commented on "happenings registered as events" (Hastrup I995, 52) in which ethnographers participate, sharing the situation and movement with other subjects.

I3 Infrastructures remain particularly significant in the contexts of postcolonial states, and relate there to hierarchies and access to goods. At the same time, the experience of modern infrastructures is part of the identities of ethnographers, who mostly originate from groups that are privileged on a global scale. I discuss methods of opening and sharing infrastructures as a project of questioning these asymmetries.

I4 Even though visual and audio media have historically provided platforms to consolidate the hegemony of the spectacle (Debord 20IO), they can also contribute to the encounter of many attitudes and voices from outside centres of power (Deger 2013, Ginsburg 1995). In anthropology and ethnology, the role of audiovisual technologies similarly reflects this duality. On the one hand, colonial photographic and phonographic archives served administrative ideologies of supremacy, but on the other, projects such as Jean Rouch's films undermined epistemological and aesthetic domination in the visual field (Rouch and Feld 2003). 
of life and the necessity to lead a struggling existence in a modern African city. Last but not least, it informed me about connections between the global music market and academia.

The recording of live performed music took the central role in the happening. In 20I6, the Tonga Boys and I conducted four recording sessions at the houses of band members and their friends ${ }^{15}$. They performed music that referred to many sound environments. A large part of these songs were thematically associated with villages on Lake Malawi, identified as the origin of the Tonga tribe. They sang about shortcuts in the forests and spots by the lake. On the other hand, a common motif was also immigration. Several band members, like hundreds of thousands of men from northern Malawi, had worked for a time in South Africa ${ }^{16}$. Finally, the instrumental arrangements were connected to the everyday environment of their lives. The only semi-professional drum (more similar to a West African djembe than the native ngoma) was supplemented by plastic and tin buckets, an axe blade and other items of basic household appliances.

After 2016, I finished the post-production of the songs in a studio in Poland and published a CD, after signing a contract with the band confirming $90 \%$ of the sales for the group. The post-production emphasized the conditions of the recordings and relations with other social spaces, rather than exoticism. The final sound was related to an ethnographic critique of hegemonic representation, and aimed to reveal the contradiction of the everyday experiences of musicians and listeners ${ }^{17}$. As a result, the songs have gained new meanings in distanced social environments.

Since then, we have been in continuous contact, as long as they had funds to buy telephone credits. During my fieldwork in 2019, we conducted the next three recording sessions, and had many conversations about the further aims of the band. During these discussions, Tonga Boys referred to their work reflexively, identifying it in relation to local styles and sound environments. Their self-definition critically reconstructed both official and local identity discourses. In the Malawian state, each officially recognized "tribe" is assigned with a specific dance and music style. Within the terms of this categorisation, reproduced by primary level schooling during performative art

I5 During each of the first four sessions (carried out at the same time as the street recordings of Chibavi), I utilized a stereophonic microphone Rode $\mathrm{NT}_{4}$ connected to a Tascam DR4 digital recorder. Encouraged by the band members, I videotaped parts of the session using one or two midresolution video hand-cameras.

I6 These migrations have shaped the social landscape of the whole region for at least a hundred and fifty years.

17 The reviewer from the online music magazine Roots World interpreted these artistic aims as follows: With rhythms often in 4/4, there's a familiarity here, a sense of connection with so much pop music the world over. Yet, there is nothing slick about any of this; it's straight up, hardcore, crude-by-necessity Malawian modernity (Miller 20I7). 
classes, the local malipenga dance is assigned to the identity of the Tonga people. Of course, the present practice of performing these dances does not easily match the historical tribal boundaries affirmed by the administration. Tonga Boys considered that instead of malipenga, their style might rather be associated with vimbuza, officially characterised as an immanent part of the culture of the Tumbuka people. While dancers perform malipenga in a celebratory context, as a burlesque of military parades, vimbuza has spiritual affinities. It is a healing dance for possessed patients affected by "spiritual disease" (Friedson 1996, Soko 2014). During the dance, the spirits, animated by the rhythm, introduce themselves (sonically and by movement) through dancing bodies. Later, they calm down after receiving offerings prepared for their satisfaction. Some of those possessed, who have a constant relationship with spirits, start a medical practice. Their healing concerns both solving health problems (using herbs also indicated by the spirits), and prophecizing about their causes, usually either witchcraft or possession. This happens during dances and dreams.

Members of the Tonga Boys have encountered vimbuza several times in their lives. One of them, when he once moved back from the city to the countryside, was attacked by the witchcraft of a certain madala (old man) from his home village. He explained that he owes his life to one of the spiritually possessed doctors (sing'anga), who removed the charm and applied suitable protective medicines. Others as children attended night vimbuza sessions, clapping their hands as others gathered and thus increasing the rhythm that allowed spirits to rise. The next day they usually fell asleep at school.

One day I shared with Albert Manda my plan to visit doctor Kanuska Msowoya, a recommended sing'anga and vimbuza dancer. Albert, who had experiences with traditional medicine, expressed interest in my idea and thereupon, from word to word, we coined a plan for a joint visit to her thempili (temple). We decided to ask her for a collective recording session and a diagnosis of the problem of the Tonga Boys, who, despite the two released CDs, suffered from poverty and "bad luck". We soon presented the idea to the other band members, who acquiesced.

\section{DIGITALIZING THE SOUNDS OF SPIRITS}

Some days later I moved from the biggest city of the region, Mzuzu, to the village Katula, several dozen kilometres north. I stayed there with one of the band members. He was the only Tonga Boy living outside the city and, as a teacher in a primary school, the only one with a full-time job. The village was located a few kilometres from Kanuska Msowoya's thempili. We soon went there with my host. In a respectful conversation, she agreed to the band's visit, and the recording and medical diagnosis for the musicians. The Tonga Boys came to Katula a few days later, whereupon we soon set off for Doctor Msowoyàs house. As a result of getting lost after using 
a shortcut, we arrived at her place long after dark. On arrival, we were allowed to rest for a while and were fed a meal of typical nsima (a staple food from maize) with chicken, which usually indicates an honourable welcome. During the meal, I installed the recording equipment in the thempili, while being attentively observed by young people and children gathering in expectation of the ceremony. I placed microphones under the thatched roof, strengthened with massive wooden boughs and foil ${ }^{18}$. After performing these technical activities, I returned to Doctor Msowoya's house, where the band members talked about the upcoming performance. They were instructed that the evening would begin with a prayer, then one of the possessed patients would dance. Later they should perform five songs as guests. Knowing this, they discussed the tracklist.

After an hour or two, over a dozen people entered the room in which we waited. Among them were Kanuska Msowoya and her patients (i.e. people possessed by vimbuza spirits) dressed in white and red attires with crosses, as well as children from the choir of the nearby African Chipangano (Eng. Covenant) Church. In a procession led by the doctor, we moved to the temple in the complete darkness of a new moon night. Patients and honourable guests (walendo), including us, took a seat on the platform. I decided to step aside from the dais in order to control the recording equipment. Doctor Maphiri, one of Doctor Msowoya's patients, was about to start the dance. At first, he sat down next to three drums, so the exploding resonance hit his body directly. After a few minutes, he began to shake and moan, and finally got up and started to take steps. He danced for a total of approximately one hour, pausing every few minutes to speak up and diagnose viewers' illnesses. Shortly after, the Tonga Boys began their performance and the crowd got even denser ${ }^{19}$. Children were sitting on the floor, young people pushed to get closer, and on the platform some elders stood up to view the band. The vocalist of the Tonga Boys, Peter Kaunda, called to the crowd to sing along in a pop-singer-like manner. Three drummers of Kanuska's orchestra joined in, playing a spiritual vimbuza beat in their routine style. The motoric beat added a new pulsation to the songs performed by the band. Among these songs, there

I8 For this session, I prepared a Rode $\mathrm{NT}_{4}$ microphone to capture the complete scene. I used a SM 58 dynamic microphone to collect sound from the main of the three drums used in vimbuza. I connected the microphones to the SoundDevice MixPre3 audio interface, using the three available inputs. Except for this session, I also often utilized a contact microphone for recording a signal from a percussion instrument. This time, however, because I was working in a new environment and preferred to access it gradually, not necessarily by concentrating on a more sophisticated cabling system, I skipped this additional microphone.

I9 It is risky to assume a clear distinction that Maphiri's dance was spiritual and the performance of the Tonga Boys, merely entertainment. Although this thought occurred to me, Kanuska Msowoya increased my doubts by pointing out at subsequent meetings that serving a chicken for guests was a spiritual practice. 


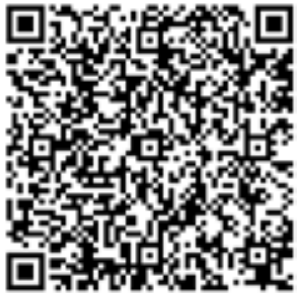

Zaninge Kwa Yehova

was a tune from vimbuza ceremonies in the band's native area of Nkhata Bay. A few people from Doctor Msowoya's team started clapping and adding a secondary voice. Peter performed a few dance steps resembling the vimbuza. When they completed presenting the fifth song and withdrew to the back, I halted the recording ${ }^{20}$.

This extensive account reveals the entanglement of practices from various social and sound environments ${ }^{21}$. It can therefore be seen as an example of a situationist event, in which performed and recorded sound reveals and creates a constellation of relationships. Urban music, in the specific example of the Tonga Boys' songs, relates to rural vimbuza $a^{22}$, but only indirectly (as it also has some resemblances with rhythmic arrangements of catholic gospel from Malawi). Vimbuza and urban music do not co-occur in one sound environment. The practices of these two sound environments usually stand in contradiction to one another. For example, the performance of pop music requires control over its flow: i.e. through a tracklist (as the Tonga Boys intended). On the contrary, vimbuza works through the suspension of human subjectivity, as in the uncontrolled (or rather controlled by non-human forces) dance. The most important difference for my interlocutors from the city was the presence of vimbuza spirits, who are supposed to be the opposite of the Holy Spirit. The performers, however, rarely conceptualize the relationships between these different sound environments. It is anthropologists who make a claim for the insights to be gained by comparative reflection. The possibility of the interplay between vimbuza and urban music was perhaps animated by this need of comparison; but it was also the result of a co-operation between anthropologist and performers, of their "alliance" for knowledge (Turkle 2008, 7-8).

20 During the same night, I continued recordings and registered, with Doctor Msowoya’s permission, a few dozen vimbuza themes performed in a ritual context. Audio recording Tonga Boys and Group Kanuska - Zaninge Kwa Yehova:

https://rcin.org.pl/Content/I22009/Audio/WA308 I52210 P366 Ethnography-Listenin 00002.mp3.

The other problem of key importance is the role of technology in the recording process. Because of the limited space and the fact that I addressed this topic elsewhere (Cichocki 20I9), I can only list some of the most important aspects. Among them are the issues of control over and through technology; the differences in understanding the role of technology between the ethnographer and other people participating in the situation; the role of technological devices as provocateurs; last not least the question of what elements failed to be registered due to the limits of the technological inscription.

22 In the eighties, Friedson observed vimbuza rituals in the centre of Mzuzu (Friedson 1994). 25 years later I participated in them, at best, hidden in the suburbs, or more openly in smaller towns and villages. 
The meeting of the Tonga Boys and the people of Doctor Msowoya enabled the emergence of a new sound happening. It was both ephemeral as an action and documented as a recording. The registration of this musical performance provoked, therefore, an experimental combination of several environments: Mzuzu city, vimbuza villages and global data networks.

The first of these environments was Mzuzu city, or more specifically its poorer districts where the Tonga Boys lived. As demonstrated in the previous section on the arrangement of Tonga Boys' songs, the city sound and city life emerge in them from a combination of varied elements. The band members, feeling nostalgia for rural life, played music that modified motifs from the villages of the Nkhata Bay district. This nostalgia combines with an amalgam of objects and styles to build a noisy, multilayered sound environment.

The villages around Enukweni and Katula formed the second environment. This space is marked by the thunderous drums that accompany the vimbuza. There, vimbuza is an almost everyday vehicle which links together the domains of music, dance, intangible beings, dreams, medicine, botany and people. In local practice, they are entangled in the spiritual sound environment of vimbuza.

Thirdly, the performance from the thempili of Doctor Msowoya also relates to the virtual environment formed by digital infrastructures of data distribution. Earlier, I described this environment using the term "repository". As mentioned above, we can understand the repository as a cumulative data storehouse (like the Internet). This storehouse is subdivided into such categories as music and entertainment or scientific recordings and papers. The sound recordings and academic analysis of that night's events will be located in these virtual environments. This process will separate the effects from the momentum of the performance. In the virtual environment, the sound becomes a file, but this file has a potential of evoking an imaginary shape and meaning of the event.

Furthermore, this event also explained how vimbuza was perceived, felt and performed by migrants from villages who had gone to look for "greener pastures" (as they say in Malawi) in the city, and by a newcomer from Europe ${ }^{23}$. Yet, the situation also gave me the no less important question of how the records produced during ethnographic research can be recontextualized by people practising vimbuza in the Malawian village or by dwellers of poor city suburbs. Hence, this is a narrative about a convergence of multiple practices and methods to produce meaning in performance, initiated by the technological practice of sound recording.

23 The question of how vimbuza is understood and felt by listeners and reviewers from Europe or the United States approaching the albums of the Tonga Boys and shortly also by the Kanuska Msowoya Drummers adds another thread to this connection. 


\section{METHODOLOGIES OF ETHNOGRAPHIC LISTENING AND RECORDING}

The above remarks point to the relationship between people (inhabitants or strangers - ethnographers) and their sound environment. The aforementioned cases question also the documentary role of listening to and recording social practices. Following Marcus Banks, I assume that what we perceive as documentation is neither innocuous nor transparent (Banks 200I, II5). On the contrary, listening and recording are performative and, most of all, entangled in social relationships. Moreover, they are always localized and related to specific sound environments. The way we organize these practices rearranges the fieldwork, redefining its spatiality and scope. Moreover, the cases I described are not cut and paste formulas of fieldwork procedures. I have rather described multidimensional happenings that have in common a sensitivity of listening and a willingness to take action in line with the flow of social life (or also against it, if this happens in cooperation with local others).

At the same time, the interval between the recording of the Chibavi street sound and the ephemeral performance of vimbuza reveals something more. It suggests a transition: from attempts to monitor objectively to an interspersed practice of listening and recording. The ethnographic subject gradually shifts from listening to a landscape to listening through the environment. The first steps of the research constituted a situation of listening not inscribed in local social relations. At this point, I was attempting to apprehend the general "shape" of a given scene. Subsequently, I entered into a system of relationships in which I began to lose perspective ${ }^{24}$. In so doing, I gained confidence in tracking my interlocutors and finding newly comprehended possibilities of acquiring emerging knowledge. As such, I would describe my general methodological attitude as a movement. This approach finds its inspiration in a range of anthropological concepts, such as "traces" (Derrida 1996), "lines" (Ingold 2007), and "grains" (Stoler 2009), which concern both substantiality and embodiment. Hence, the methodological proposition of reflexive listening and recording corresponds with the core paradigms of anthropology. It seeks other forms of knowledge about diverse social worlds and the connections between them. I argue that attentive listening and recording offer a variant of ethnographic subjectivity, in which perception, the body and their technological extensions unlock new possibilities of understanding.

\section{BIBLIOGRAPHY}

B a n k s M. 200I. Visual Methods in Social Research. London: Sage.

B e n d i n er-Vian i G. 2005. Walking, Emotion, and Dwelling: Guided Tours in Prospect Heights, Brooklyn. Space and Culture 8 (4), 459-47I.

24 I argue that the questioning of perspective might be a positive practice, that is a potential critique of the hegemonic oculocentric model. 
C i ch o ck i P. 20I8. Tłumacze, Imitatorzy i Afrykańscy Proletariusze. Jednodniówka Kosmopolitania I. $\mathrm{C}$ i ch o ck i P. 20I9. Production of Sound, Production of Knowledge. Central Africa, Central Europe, Global Networks. Seismograf (special issue: Sonic Argumentation II) 2.

Ci ch o cki P. and W i e c z o r e k M. 20I8. 6oo Uderzeń Na Minutę. Rozmowa z Piotrem Cichockim. Dwutygodnik, 2018.

https://www.dwutygodnik.com/artykul/8099-60o-uderzen-na-minute.html (accessed oI.09.2019).

D e C e r t e a u M. 1984. The Practice of Everyday Life. Berkeley: University of California Press.

D e b o r d G. 1957. Report on the Construction of Situations. (pamphlet).

D e b o r d G. 20io. The Society of the Spectacle. Detroit: Black \& Red.

D e g e r J. 20I3. In-Between. In A. Schneider and C. Wright (eds.), Anthropology and Art Practice. London: Bloomsbury, IO5-13.

D e l e u ze G. and G u a t t a r i F. 1987. A Thousand Plateaus: Capitalism and Schizophrenia. Minneapolis: University of Minnesota Press.

D e r r i d a J. 1996. Archive Fever: A Freudian Impression. Chicago: University of Chicago Press.

D ibben N. and Ha a ke A. B. 2013. Music and the Construction of Space in Office-Based Work Settings. In G. Born (ed.), Music, Sound and Space, Cambridge: Cambridge University Press, I5I-I68.

F a u b i o n J. D. and M a r c u s G. E. 2009. Fieldwork Is Not What It Used to Be: Learning Anthropology's Method in a Time of Transition. Ithaca: Cornell University Press.

Feld S. 1982. Sound and Sentiment: Birds, Weeping, Poetics, and Song in Kaluli Expression. Durham: Duke University Press.

F o u c a u lt M. 1977. The Archaeology of Knowledge. New York: Pantheon Books.

Fr i e d s o n S. M. 1996. Dancing Prophets: Musical Experience in Tumbuka Healing. Chicago Studies in Ethnomusicology. Chicago: University of Chicago Press.

G in s bu rg F. 1995. Mediating Culture: Indigenous Media, Ethnographic Film, and the Production of Identity. In Deveraux L. and Hillman R. (eds.) Fields of Vision: Essays in Film Studies, Visual Anthropology and Photography, Berkeley: University of California Press, 256-290.

$\mathrm{H}$ a b e r m a s J. 1987. Knowledge and Human Interests. Cambridge: Polity Press.

$\mathrm{H}$ a s $\mathrm{r}$ u p K. 1995. A Passage to Anthropology: Between Experience and Theory. New York: Routledge.

In gold T. 2007. Against Soundscape. In T. Ingold Autumn Leaves: Sound and the Environment in Artistic Practice. Paris: Double Entendre.

In g o ld T. 2016. Lines: A Brief History. London: Routledge.

$\mathrm{M}$ a s s u m i B. 20I5. Politics of Affect. Cambridge and Malden: Polity.

Mille r B. 2017. Kukaya and Tonga Boys: A RootsWorld Review. Roots World.

http://www.rootsworld.com/reviews/Iooohz-I7.shtml (accessed oI.09.2019).

Nov a k D. 2013. Japanoise: Music at the Edge of Circulation. Durham: Duke University Press.

Novak D. and S a ka ke en y M. (eds.) 20I5. Keywords in Sound. Durham and London: Duke University Press.

Pe t $\mathrm{t}$ a $\mathrm{n}$ S. and T i t o n J. T. (eds.) 2015. The Oxford Handbook of Applied Ethnomusicology. Oxford and New York: Oxford University Press.

P in k S. 200I. Doing Visual Ethnography: Images, Media, and Representation in Research. London and Thousand Oaks: Sage.

R a b i n ow P. 1977. Reflections on Fieldwork in Morocco. Berkeley: University of California Press.

Rice T. 2003. Time, Place, and Metaphor in Musical Experience and Ethnography. Ethnomusicology 47 (2), I5I-I79.

Rou ch J. and Feld. S. 2003. Ciné-Ethnography. Visible Evidence, v. I3. Minneapolis: University of Minnesota Press. 
S ch n e i d e r A. and Wri g h t C. (eds.) 20Io. Between Art and Anthropology: Contemporary Ethnographic Practice. Oxford and New York: Berg Publishers.

S ch n e id e r A. and Wrigh t C. (eds.) 2013. Anthropology and Art Practice. New York: Bloomsbury Academic.

Schumaker L. 20oI. Africanizing Anthropology: Fieldwork, Networks, and the Making of Cultural Knowledge in Central Africa. Durham: Duke University Press.

Sl o t e r d i j k P. 20I6. Spheres: Volume 3: Foams Plural Spherology. South Pasadena: Semiotext.

S o k o B. 20I4. Vimbuza: The Healing Dance of Northern Malawi. Zomba: Imabili Indigenous Knowledge Publications.

S t e r n e J. 20I5. Hearing. In D. Novak and M. Sakakeeny (eds.) Keywords in Sound, edited by David Novak and Matt. Durham: Duke University Press, 65-77.

S t o 1 e r A. L. 2009. Along the Archival Grain: Epistemic Anxieties and Colonial Common Sense. Princeton: Princeton University Press.

Th o m p s o n E. A. 2008. The Soundscape of Modernity: Architectural Acoustics and the Culture of Listening in America, 1900-1933. Cambridge: MIT Press.

Tu r kl e S. 2008. The Inner History of Devices. Cambridge: MIT Press.

Weheliye A. G. 2005. Phonographies Grooves in Sonic Afro-Modernity. Durham: Duke University Press.

\section{Author's contact:}

Piotr Cichocki

Institute of Ethnology and Cultural Anthropology University of Warsaw

Email: piotrcichocki8I@gmail.com

ORCID: oooo-0oo3-0999-477X

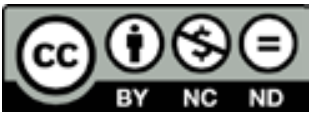

